\title{
A Unique Role of RGS9-2 in the Striatum as a Positive or Negative Regulator of Opiate Analgesia
}

\author{
Kassi Psigfogeorgou, ${ }^{1}$ Dimitra Terzi, ${ }^{1}$ Maria Martha Papachatzaki, ${ }^{1}$ Artemis Varidaki, ${ }^{1}$ Deveroux Ferguson, ${ }^{2}$ \\ Stephen J. Gold, ${ }^{3}$ and Venetia Zachariou ${ }^{1}$ \\ ${ }^{1}$ Department of Pharmacology, University of Crete Faculty of Medicine, 71003 Heraklion, Greece, ${ }^{2}$ Fishberg Department of Neuroscience, Mount Sinai \\ School of Medicine, New York, New York 10029-6574, and ${ }^{3}$ Metabolic Disorders Merck Research Laboratories, Rahway, New Jersey 08889-0100
}

The signaling molecule RGS9-2 is a potent modulator of G-protein-coupled receptor function in striatum. Our earlier work revealed a critical role for RGS9-2 in the actions of the $\mu$-opioid receptor (MOR) agonist morphine. In this study, we demonstrate that RGS9-2 may act as a positive or negative modulator of MOR-mediated behavioral responses in mice depending on the agonist administered. Paralleling these findings we use coimmunoprecipitation assays to show that the signaling complexes formed between RGS9-2 and G $\alpha$ subunits in striatum are determined by the MOR agonist, and we identify RGS9-2 containing complexes associated with analgesic tolerance. In striatum, MOR activation promotes the formation of complexes between RGS9-2 and several G $\alpha$ subunits, but morphine uniquely promotes an association between RGS9-2 and G $\alpha$ i3. In contrast, RGS9-2/G $\alpha$ q complexes assemble after acute application of several MOR agonists but not after morphine application. Repeated morphine administration leads to the formation of distinct complexes, which contain RGS9-2, G $\beta 5$, and G $\alpha$ q. Finally, we use simple pharmacological manipulations to disrupt RGS9-2 complexes formed during repeated MOR activation to delay the development of analgesic tolerance to morphine. Our data provide a better understanding of the brain-region-specific signaling events associated with opiate analgesia and tolerance and point to pharmacological approaches that can be readily tested for improving chronic analgesic responsiveness.

\section{Introduction}

The $76 \mathrm{kDa}$ protein RGS9-2 plays a potent modulatory role in striatal function by controlling responsiveness of several G-proteincoupled receptors (GPCRs) (Rahman et al., 1999, 2003; CabreraVera et al., 2004; Kovoor et al., 2005; Terzi et al., 2009; Traynor et al., 2009). RGS9-2 is the brain-specific splice variant of the RGS9 gene and member of the R7 group of the regulator of G-protein signaling (RGS) family, abundantly expressed in all types of striatal neurons (Gold et al., 1997; Rahman et al., 2003; Cabrera-Vera et al., 2004). In vitro work has proved that RGS9-2 interacts with activated $\mathrm{G} \alpha$ subunits to promote their GTPase activity (Dohlman and Thorner, 1997; Berman and Gilman, 1998; Terzi et al., 2009), but the G $\alpha$ subunit selectivity for RGS9-2 in the striatum remains unknown. In addition to the conserved RGS region, RGS9-2 contains an N-terminal DEP domain that mediates association with cell membrane adaptor proteins (Martemyanov et al., 2003, 2005; Ballon et al., 2006; Jayaraman et al., 2009), a GGL ( $\mathrm{G}$ gamma like) domain that promotes stability by binding to G $\beta 5$ protein (He et al., 2000; Chen et al., 2003), and a C-terminal phosphodiesterase $\gamma$-like domain (Rahman et al., 1999). All these domains play important roles in RGS9-2 actions by controlling

\footnotetext{
Received Aug. 6, 2010; revised Feb. 7, 2011; accepted Feb. 11, 2011.

Author contributions: S.J.G. and V.Z. designed research; K.P., D.T., M.M.P., A.V., and D.F. performed research; K.P., D.T., and V.Z. analyzed data; S.J.G. and V.Z. wrote the paper.

This work was supported by Greek General Secretariat for Research and Technology Grant PENED03-860.

Correspondence should be addressed to Venetia Zachariou, Department of Pharmacology, University of Crete, 71003 Heraklion, Greece. E-mail: vzachar@med.uoc.gr.

DOI:10.1523/JNEUROSCI.4146-10.2011

Copyright $\odot 2011$ the authors $\quad 0270-6474 / 11 / 315617-08 \$ 15.00 / 0$
}

the protein stability, localization, or its interactions with other proteins. Because recent studies reveal that manipulations of RGS9-2 levels in the striatum may potently modulate pharmacological responses (Rahman et al., 2003; Zachariou et al., 2003; Kovoor et al., 2005; Traynor and Neubig, 2005; Gold et al., 2007), it is essential to understand the mechanism via which RGS9-2 modulates different GPCRs in this brain region. Opiate analgesics, including morphine, fentanyl, and methadone, exert their actions via activation of the G-protein-coupled $\mu$-opioid receptor (MOR) (Contet et al., 2004). Morphine is a very efficient analgesic, but clinicians limit its use because of numerous side effects, the development of analgesic tolerance, and its significant abuse potential (Kreek, 2001). Our previous work demonstrated that RGS9-2 is a negative modulator of the analgesic and rewarding actions of morphine (Zachariou et al., 2003). Using cell culture models, we have shown that RGS9-2 associates with MOR and affects several events that follow MOR activation, including the phosphorylation of extracellular signal-regulated kinase (ERK) and the rate of receptor internalization (Psifogeorgou et al., 2007). Here, we use behavioral and biochemical assays to investigate the role of RGS9-2 in MOR signaling in striatum. At the behavioral level, RGS9-2 is a negative modulator of morphine actions but acts as a positive modulator of the analgesic actions of fentanyl and methadone. Our biochemical findings suggest that this difference results from the formation of distinct complexes in striatum between RGS9-2, G $\alpha$ subunits, and other signal transduction elements, after activation of MOR by different agonists. Our coimmunoprecipitation data reveal that changes in the composition of these complexes after chronic morphine administra- 
tion correlate with the development of analgesic tolerance. Finally, we developed simple pharmacological manipulations to prevent the formation of stable RGS9-2-containing complexes to delay analgesic tolerance to morphine.

\section{Materials and Methods}

Mouse breedings and treatments. RGS9 mutant mice used in this study (Zachariou et al., 2003) were generated from breedings of heterozygous RGS9 knock-out (KO) mice (backcrossed for 16 generations onto C57BL/6 background). For all behavioral assays, we used naive 2-monthold male KO mice and their wild-type (WT) littermates. For immunoprecipitation assays, striata were extracted $30 \mathrm{~min}$ after saline, fentanyl, methadone, or morphine injections (Charlton et al., 2008). For immunoblotting analysis, tissue from 2-month-old C57BL/6 mice was extracted 10 and $20 \mathrm{~min}$ after saline or drug treatment as described (Zachariou et al., 2003). Animals were housed in a $12 \mathrm{~h}$ dark/light cycle room according to the animal care and use committees of Mount Sinai Medical Center and the University of Crete. Chronic treatments for immunoprecipitation assays involved subcutaneous injections of increasing morphine (from 15 to $80 \mathrm{mg} / \mathrm{kg}$ ) or fentanyl (from 0.04 to 0.32 $\mathrm{mg} / \mathrm{kg}$ ) doses given twice per day for $4 \mathrm{~d}$ and the morning of the fifth day. The afternoon of the fifth day, striata were extracted 30 min after morphine $(20 \mathrm{mg} / \mathrm{kg})$ or fentanyl $(0.125 \mathrm{mg} / \mathrm{kg})$ injection.

Coimmunoprecipitation and Western blot assays. Western blot analysis studies were preformed as described previously (Charlton et al., 2008). For immunoprecipitation (IP) assays, striatal tissues of mice treated with saline, morphine, or fentanyl for 30 min were rapidly dissected as describer previously (Charlton et al., 2008). Briefly, samples were centrifuged for $30 \mathrm{~min}$ at 13,000 rpm, and cell lysates were subjected to a second centrifugation for 20 more min [lysis buffer: $20 \mathrm{~mm}$ Tris- $\mathrm{HCl}, \mathrm{pH} 7.5$, $150 \mathrm{~mm} \mathrm{NaCl}, 0.1 \%$ Triton X-100, 1 mM EDTA, $1 \times$ protease inhibitor cocktail (P8430; Sigma), and $0.2 \mathrm{~mm}$ sodium orthovanadate (Sigma)]. Lysates were precleared with $20 \mu \mathrm{l}$ of $\mathrm{G}$ agarose beads (Roche) by $1-2 \mathrm{~h}$ incubation at $4^{\circ} \mathrm{C}$. Immunoprecipitation was performed by incubating the supernatants with primary antibody of interest overnight (Charlton et al., 2008). The following antibodies were used for IP and Western blot assays: rabbit protein A-purified anti-RGS9 antibody $(1: 10,000)$ (Psifogeorgou et al., 2007) (supplemental Fig. $1 d$, available at www.jneurosci. org as supplemental material) and a rabbit anti-G $\beta 5$ (C terminus) antibody (1:10,000; W. Simonds, National Institute of Diabetes, Digestive, and Kidney Diseases, Bethesda, MD), rabbit anti-MOR (1:1000; Immunostar) (Arvidsson et al., 1995; Haberstock Debic et al., 2005; Jin et

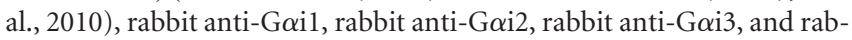
bit anti-G $\alpha$ s (1:1000; all provided by S. Mumby, University of Texas Southwestern Medical Center, Dallas, TX) (Mumby and Gilman 1991), rabbit anti-G $\alpha$ q (1:1000; Paul Sternweis, University of Texas Southwestern Medical Center), rabbit anti-GRK2 (1:1000; Millipore), rabbit antiphosphorylated phospholipase C $\beta 3$ (pPLC $\beta 3$ ) or anti-PLC $\beta 3$ (1:400; Cell Signaling Technology), and rabbit anti- $\beta$-arrestin-2 (1:1000; J. Benovic, Thomas Jefferson University, Philadelphia, PA) (Mundell et al., 1999). For ERK phosphorylation assays, we used a mouse pERK antiserum and a purified rabbit ERK antiserum (1:1000; Sigma).

Analgesia and tolerance studies. Analgesia was measured using the $52^{\circ} \mathrm{C}$ hotplate test, as described previously (Zachariou et al., 2003). For analgesic tolerance assays, mice were monitored at baseline and $30 \mathrm{~min}$ after drug administration for 4 consecutive days. All hotplate data are expressed as percentage maximal possible effect $[\mathrm{MPE}=($ latency - baseline $) /($ cutoff latency)]. A cutoff time of $40 \mathrm{~s}$ has been used in all hotplate experiments.

\section{Results}

Ligand-dependent effects of RGS9-2 on behavioral responses Our previous behavioral studies demonstrated that functional deletion of the RGS9 gene increases sensitivity to morphine reward and analgesia and delays the development of analgesic tolerance (Zachariou et al., 2003, Psifogeorgou et al., 2007). To assess whether the effects of RGS9-2 deletion generalized to other MOR agonists, we used the $52^{\circ} \mathrm{C}$ hotplate assay and compared responses of RGS9 wild-type (RGS9 WT) and RGS9 knock-out

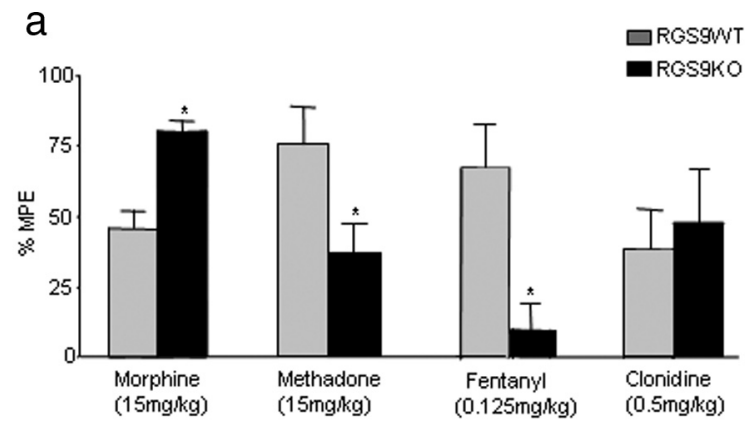

b

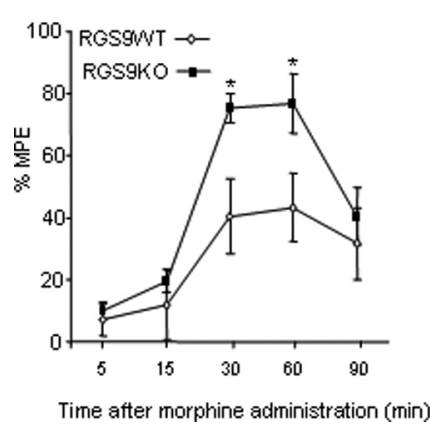

$\mathrm{c}$

Figure 1. Differential regulation of the analgesic actions of morphine, methadone, and fentanyl by RGS9. $\boldsymbol{a}$, Mice lacking the RGS9 gene show increased analgesic response to morphine $(15 \mathrm{mg} / \mathrm{kg}$, s.c.) in the hotplate test. Conversely, RGS9KO mice show a reduced response to the opioid analgesics methadone ( $15 \mathrm{mg} / \mathrm{kg}$, s.c.) and fentanyl $(0.125 \mathrm{mg} / \mathrm{kg}$, s.c.) compared with their wild-type littermates. Administration of the $\alpha_{2}$-adrenergic receptor agonist clonidine $(0.4$ $\mathrm{mg} / \mathrm{kg}$ ) did not reveal any significant difference in the analgesic response between genotypes. In the hotplate assay, knockout of RGS9 leads to increased response to morphine $(10 \mathrm{mg} / \mathrm{kg})$ without affecting the onset or duration of analgesia $(\boldsymbol{b})$. c shows that the analgesic response to fentanyl $(0.125 \mathrm{mg} / \mathrm{kg})$ in RGS9KO mice are lower than that of their wild-type littermates, at different time points after drug administration. Data are expressed as means \pm SEM. ${ }^{*} p<0.05$ for genotype versus treatment, two-way ANOVA followed by Bonferroni's post hoc test.

(RGS9KO) mice to several opioid analgesics. Consistent with previous findings, RGS9KO mice show a greater analgesic response to morphine $(15 \mathrm{mg} / \mathrm{kg}$, s.c.) in the hotplate assay (Fig. $1 a)$. In contrast, mice lacking $R G S 9$ show reduced analgesic responses to methadone ( $15 \mathrm{mg} / \mathrm{kg}$, s.c. $)$ and fentanyl $(0.125 \mathrm{mg} /$ $\mathrm{kg}$, s.c.) compared with their wild-type littermate controls. At higher doses $(0.2 \mathrm{mg} / \mathrm{kg})$, fentanyl produces a significant analgesic response that is still lower than that observed in their wild-type littermates (\%MPE for RGS9WT $=80 \pm 8$ and RGS9KO $=53 \pm$ 13). The effects of RGS9-2 deletion in analgesia are specific to MOR agonists, because no phenotype is observed when the $\alpha 2$ adrenergic receptor agonist clonidine is used (Fig. 1a). Notably, the responses of RGS9KO mice to morphine and fentanyl are not related to differences in the onset or duration of analgesia between genotypes (Fig. 1b,c).

\section{Agonist-dependent formation of MOR signaling complexes in the striatum}

In an effort to mechanistically understand the agonist-selective phenotype of RGS9KO mice, we used co-IP assays to examine the composition of RGS9-2 complexes that are formed in striatum after fentanyl or morphine application. For all immunoprecipitation assays, we selected doses of fentanyl $(0.125 \mathrm{mg} / \mathrm{kg})$ and morphine $(20 \mathrm{mg} / \mathrm{kg})$ that produce maximal analgesia in C57BL/6 mice in the hotplate assay. The time point of $30 \mathrm{~min}$ was selected as the earliest time point after drug application that changes in RGS9-2 interactions were detected. First, we exam- 
Table 1. Interactions of MOR with $\mathrm{G} \alpha$ subunits

\begin{tabular}{llll}
\hline & Basal & Fentanyl & Morphine \\
\hline MOR/G $\alpha$ i1 & + & ++ & ++ \\
MOR/G $\alpha$ i2 & + & ++ & +++ \\
MOR/G $\alpha$ i3 & + & + & +++ \\
MOR/G $\alpha$ q & + & +++ & + \\
MOR/G $\alpha 0$ & + & ++ & ++ \\
\hline
\end{tabular}

Mice were treated with saline, morphine $(20 \mathrm{mg} / \mathrm{kg})$, or fentanyl $(0.125 \mathrm{mg} / \mathrm{kg})$ for $30 \mathrm{~min}$. Striatal extracts were immunoprecipitated with an anti-MOR antibody, and the immunoprecipitate was immunoblotted for G $\alpha \mathrm{i} 1, \mathrm{G} \alpha \mathrm{i} 2$, $\mathrm{G} \alpha \mathrm{i} 3, \mathrm{G} \alpha \mathrm{q}$, or $\mathrm{G} \alpha 0$. Each experiment was performed at least three times.

ined the interactions between MOR and $\mathrm{G} \alpha$ subunits after application of fentanyl or morphine. As shown in Table 1, activation of MOR promotes the formation of complexes with several G $\alpha$ subunits in striatum, but some of these interactions are associated with particular agonists. We recently showed that MOR activation by fentanyl (but not morphine) promotes association of the receptor with $\mathrm{G} \alpha \mathrm{q}$ proteins (Han et al., 2010). Here, we demonstrate that fentanyl application promotes the formation of complexes between MOR and the G $\alpha \mathrm{q}$ effector PLC $\beta 3$ (Fig. 2a). Conversely, MOR/G $\alpha \mathrm{i} 3$ complexes are observed only after morphine administration (Fig. $2 b$ ). The next set of IPs investigated the interactions between MOR and $\beta$-arrestin-2, an essential protein for receptor desensitization. Consistent with previous findings, activation of MOR by morphine leads to an increased association with $\beta$-arrestin- 2 in striatum ( $454 \pm 88 \%$ ) relative to saline controls (Fig. $2 c$ ). Fentanyl also promotes the formation of complexes between MOR and $\beta$-arrestin-2, but this effect is smaller than that of morphine (197 $\pm 27 \%)$. Finally, we show that RGS9-2 is part of these signaling complexes because, 30 min after activation of MOR by fentanyl or morphine, there is an increased interaction between the receptor and RGS9-2 in striatum (Fig. 2d) $(348 \pm 70 \%$ increase after fentanyl application and $560 \pm$ $97 \%$ increase after morphine, both relative to saline application).

Because our immunoprecipitation assays demonstrate that MOR interactions with both $\mathrm{G} \alpha$ subunits and $\beta$-arrestin- 2 are agonist dependent and our behavioral assays show that fentanyl and morphine produce opposite phenotypes in RGS9KO mice in the hotplate assay, we next examined the role of RGS9-2 in signal transduction complexes formed after MOR activation by these agonists. Paralleling our co-IP findings with MOR, morphine administration promotes the formation of complexes between RGS9-2 and $\beta$-arrestin-2, whereas fentanyl promotes a smaller but still significant increase in this complex compared with control conditions (Fig. 3a). RGS9-2 appears to follow the same pattern as MOR regarding agonist-dependent interactions with $\mathrm{G} \alpha$ subunits after fentanyl or morphine exposure. Specifically, al-

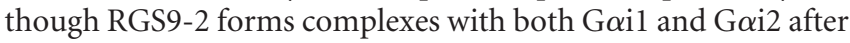
MOR activation by either fentanyl or morphine, morphine administration also promotes the formation of complexes between RGS9-2 and G $\alpha \mathrm{i} 3$ in striatum (Fig. 3b), whereas fentanyl administration promotes the association of RGS9-2 with G $\alpha$ q and with its downstream effector molecule PLC $\beta_{3}$ (Fig. $3 c, d$ ). Fentanyl treatment also promotes the association of RGS9-2 with GRK2 in the striatum ( $274 \pm 14 \%$ compared with saline-treated control). Another striking difference we observed between fentanyl and morphine is that, although both drugs promote the association of RGS9-2 to MOR, only morphine promotes the formation of RGS9-2/G $\beta 5$ complexes (Fig. 3e). This is a key finding because $\mathrm{G} \beta 5$ protein is a required binding partner for RGS9-2 stability and, in the absence of G $\beta 5$, RGS9-2 has a very short half-life (Chen et al., 2003; Witherow et al., 2003). Consistent with our behavioral findings, methadone application promotes the forma- a

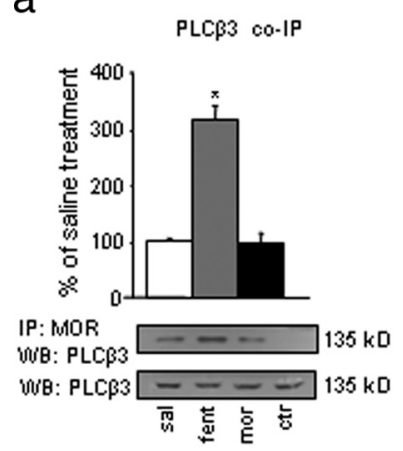

b
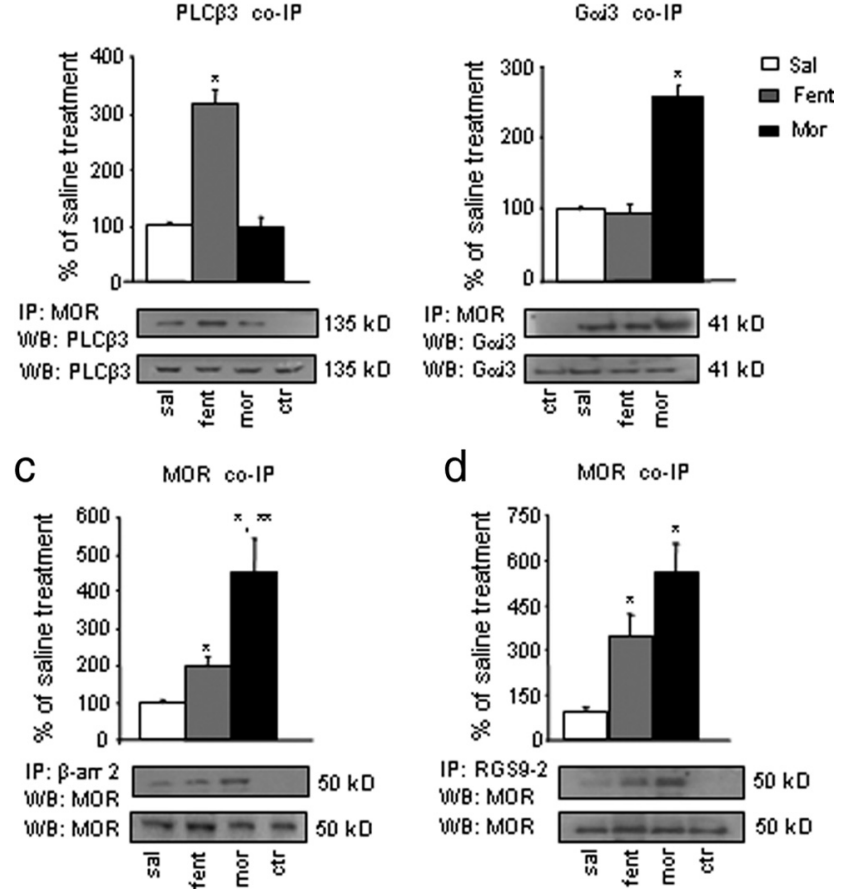

Figure 2. Morphine and fentanyl administration lead to distinct MOR signaling complexes in striatum. $\boldsymbol{a}-\boldsymbol{d}$, Mice were treated with saline (sal), morphine (mor; $20 \mathrm{mg} / \mathrm{kg}$ ), or fentanyl (fent; $0.125 \mathrm{mg} / \mathrm{kg}$ ) for $30 \mathrm{~min}$. Striatal extracts were IP with anti-MOR $(\boldsymbol{a}, \boldsymbol{b}), \beta$-arrestin-2 (c), or RGS9-2 (d) antibodies, and the immunoprecipitate was immunoblotted (WB) with the indicated antibodies. $\boldsymbol{a}, \mathrm{PLC} \beta 3$ was coimmunoprecipitated with MOR after fentanyl administration. $\boldsymbol{b}, \mathrm{G} \alpha \mathrm{i} 3$ was uniquely coimmunoprecipitated with MOR after morphine and showed low levels of interaction with MOR under baseline conditions or after fentanyl treatment. Data are expressed as means \pm SEM. ${ }^{*} p<0.01$ between treatments, one-way ANOVA followed by Dunnett's post hoc test. In c, striatal extracts were immunoprecipitated (IP) with an anti- $\beta$ arrestin-2 antibody, and the immunoprecipitate was immunoblotted (WB) for MOR. Activation of MOR by fentanyl or morphine increases its association with $\beta$-arrestin- $2\left(\boldsymbol{b} ;{ }^{*} p<0.001\right.$ for morphine and fentanyl vs saline, ${ }^{* *} p<0.05$ for morphine vs fentanyl treatment, one-way ANOVA followed by Dunnett's post hoc test). Finally, $\boldsymbol{d}$ shows that MOR is immunoprecipitated with RGS9-2, and this interaction is strengthened after fentanyl or morphine application. Data are expressed as means \pm SEM. ${ }^{*} p<0.01$ between treatments, one-way ANOVA followed by Dunnett's post hoc test. For all experiments, $n=4-5$ per treatment group. Ctr (control), Striata from morphine-treated mice immunoprecipitated with an anti-flag antiserum. WB for protein levels in total lysates are shown below each IP blot.

tion of signal transduction complexes similar to those observed with fentanyl (supplemental Fig. 1, available at www.jneurosci. org as supplemental material).

\section{Regulation of ERK and PLC $\beta 3$ phosphorylation by RGS9-2}

Because our coimmunoprecipitation results demonstrate that RGS9-2 may form complexes containing G $\alpha$ q or G $\alpha$ i subunits in striatum, we hypothesized that deletion of the RGS9 gene will affect the activity of their respective effector molecules. In particular, we examined the role of RGS9-2 in MOR-induced phosphorylation of ERK and PLC $\beta 3$. Previous studies in cell culture models showed that RGS9-2 overexpression prevents induction of pERK levels by MOR agonists (Psifogeorgou et al., 2007). In the brain, morphine may increase or decrease ERK phosphorylation, depending on the neural circuit and drug dose (Eitan et al., 2003; Muller and Unterwald, 2004). Figure $4 a$ shows that, in the nucleus accumbens (NAc), systemic administration of a low morphine dose leads to a decrease in pERK levels. This reduction is more pronounced in RGS9KO mice. Fentanyl administration also reduces ERK phosphorylation in the NAc. However, and in 
a B-ar-2 co-IP

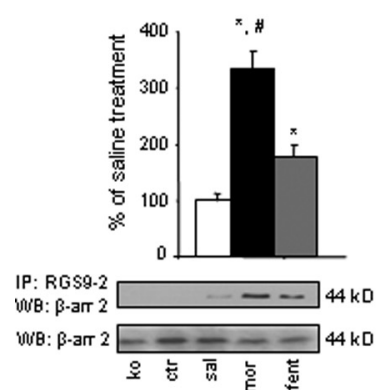

C

Gqq co-IP

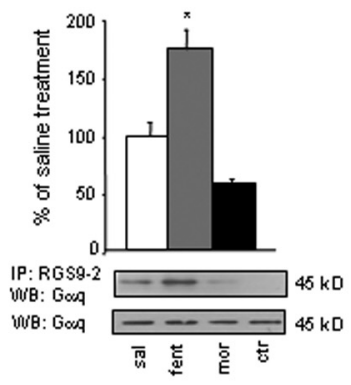

d
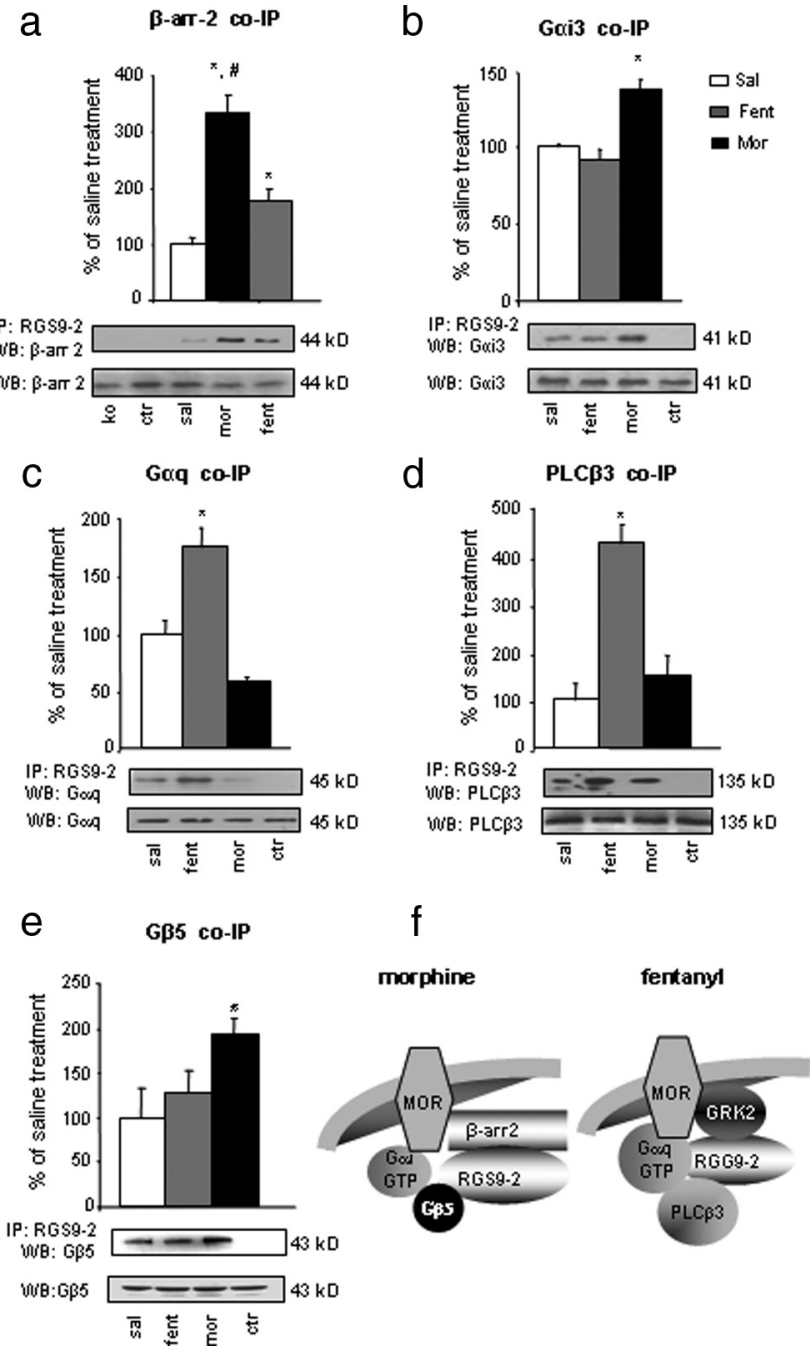

Figure 3. RGS9-2 forms distinct signaling complexes in striatum after morphine and fentanyl administration. $\boldsymbol{a}$, Mice were treated with saline (sal), morphine (mor; $20 \mathrm{mg} / \mathrm{kg}$ ), or fentanyl (fent; $0.125 \mathrm{mg} / \mathrm{kg}$ ) for $30 \mathrm{~min}$, as in the previous figure. Striatal extracts were immunoprecipitated (IP) with an anti-RGS9-2 antibody, and the immunoprecipitate was immunoblotted (WB) for $\beta$-arrestin-2 ( $\beta$-arr-2). Activation of MOR leads to an increase in RGS9$2 / \beta$-arrestin-2 complex in striatum, an effect that is more prominent during morphine administration $\left({ }^{*} p<0.05\right.$ between fentanyl and saline or morphine and ${ }^{\#} p<0.001$ between morphine and saline). $\boldsymbol{b}$, Activation of MOR by morphine (but not fentanyl) increases the association between RGS9-2 and G $\alpha$ i3. $\boldsymbol{c}, \boldsymbol{d}$, Conversely, fentanyl application promotes the formation of signaling complexes between RGS9-2 and $\mathrm{G} \alpha \mathrm{q}$ ( $\boldsymbol{c}$ ) and between RGS9-2 and PLC $\beta 3$ (d). Finally, morphine but not fentanyl application drives the formation of complexes between RGS9-2 and G $\beta 5(\boldsymbol{e})$. For all experiments, $n=3-6$ per treatment group. KO, Striata from morphine treated RGS9KO mice; (tr (control), striata from morphine-treated mice immunoprecipitated with an anti-flag antiserum. WB for protein levels in total lysates are shown below each IP blot. Data are expressed as means \pm SEM. ${ }^{*} p<0.01$ between treatments, one-way ANOVA followed by Dunnett's post hoc test. $\boldsymbol{f}$ shows a schematic representation of RGS9-2 complexes formed in striatum after activation of MOR by morphine or fentanyl.

contrast to morphine, fentanyl-induced reduction of pERK is not observed in brains of RGS9KO mice (Fig. $4 b$ ).

In addition to ERK, opioids modulate the activity of PLC $\beta$ proteins, which are known downstream effectors of $\mathrm{G} \alpha \mathrm{q}$ and PKC signaling (Chakrabarti et al., 2003). We hypothesized that given the promotion of the association of both MOR and RGS9-2 with $\mathrm{G} \alpha \mathrm{q}$ by fentanyl, RGS9-2 deletion effectively removes a competitor of G $\alpha \mathrm{q} / \mathrm{PLC} \beta 3$ interactions. Thus, RGS9 deletion should increase $\mathrm{G} \alpha \mathrm{q}$ signaling by enhancing the binding and activation of $\mathrm{G} \alpha \mathrm{q}$ to its effector molecule PLC $\beta 3$. To test our
Nucleus accumbens
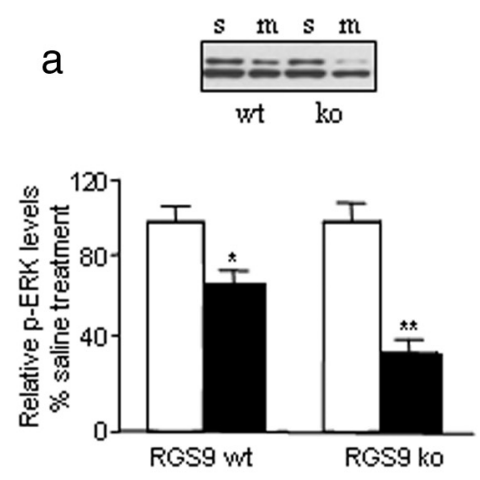

b
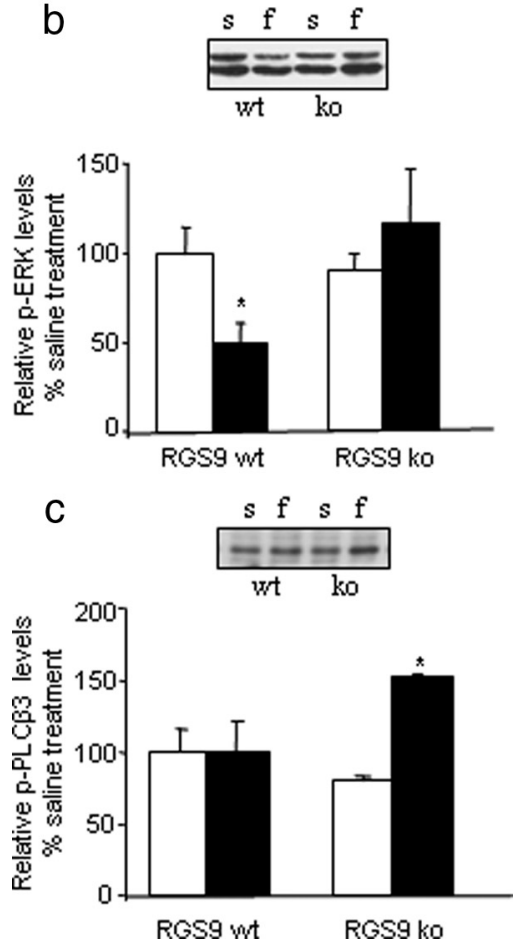

Figure 4. Modulation of ERK and PLC $\beta 3$ phosphorylation by RGS9-2. RGS9 knockout affects the pattern of ERK phosphorylation by opioids in the NAc. $\boldsymbol{a}$, Immunoblot analysis of pERK levels in NAc of RGS9WT and RGS9K0 mice 20 min after saline (s) or morphine $(\mathrm{m})(10 \mathrm{mg} / \mathrm{kg})$ administration ( $n=3$ per group). Morphine decreases pERK levels in the NAc of wild-type animals, and this effect is more pronounced when the RGS9 gene is deleted. Immunoblot analysis of pERK levels in NAc of RGS9KO mice and their wild-type controls 10 min after an injection of saline or fentanyl ( $f$ ) $(0.125 \mathrm{mg} / \mathrm{kg}$, s.c.) $(\boldsymbol{b} ; n=4-5$ per group). As indicated by the graphs, fentanyl decreases pERK levels in the NAc of RGS9WT mice, but this effect is abolished in RGS9KOs. c demonstrates changes in pPLC $\beta 3$ levels in the NAc, 10 min after fentanyl injections, in RGS9WT and RGS9KO mice. Knockout of the RGS9 gene leads to increased PPLC $\beta 3$ levels after fentanyl application. Data are expressed as means \pm SEM. $n=4$ per group; ${ }^{*} p<$ 0.05 and ${ }^{* *} p<0.01$ for genotype versus treatment, two-way ANOVA followed by Bonferroni's post hoc test.

hypothesis, we measured pPLC $\beta 3$ levels in the NAc 10 min after fentanyl injection. Figure $4 c$ shows that deletion of the RGS9 gene results in increased PLC $\beta 3$ phosphorylation in the NAc after fentanyl application. These same doses show no effect on PLC $\beta 3$ phosphorylation in samples harvested from wild-type NAc. This finding correlates with the behavioral data, which show that RGS9 deletion leads to reduced analgesic responses to fentanyl and indicate that RGS9-2 antagonizes the actions of the G $\alpha \mathrm{q}$ effector PLC $\beta 3$ in striatum. Notably, knockout of RGS9 did not affect morphine-induced PLC $\beta 3$ phosphorylation in the NAc. In 
all our pPLC $\beta 3$ studies, RGS9 deletion did not cause changes in total PLC $\beta 3$ abundance (data not shown).

\section{Chronic morphine-induced changes in RGS9-2 signaling complexes correlates with tolerance}

Because the key clinical challenge is the development of tolerance after chronic morphine treatment, our next goal was to identify possible differences in the composition of RGS9-2-containing complexes between acute and chronic MOR activation. Because morphine produces analgesic tolerance more quickly than fentanyl, we examined the composition of RGS9-2 complexes in striatum of mice repeatedly treated with fentanyl or morphine. Our preliminary studies indicated that pretreatment with a low fentanyl dose may prevent analgesic tolerance to morphine. For that reason, we included an additional group of animals that received a low fentanyl dose $30 \mathrm{~min}$ before each morphine injection. In particular, chronic morphine studies contained four groups of animals: mice chronically treated with (1) saline, (2) fentanyl, (3) morphine, and (4) a low fentanyl dose ( $0.04 \mathrm{mg} / \mathrm{kg}$, s.c.), $30 \mathrm{~min}$ before each morphine injection. On day 5 , striata were harvested $30 \mathrm{~min}$ after administration of saline, fentanyl $(0.125 \mathrm{mg} / \mathrm{kg})$, or morphine $(20 \mathrm{mg} / \mathrm{kg})$. As shown in Figure $5 a-c$, after repeated morphine exposure, activation of MOR promotes associations of RGS9-2 with MOR (Fig. $5 a$ ) (363.6 \pm 92\%), G $\alpha$ q (Fig. 5b) (216 \pm $39 \%$ ), and G $\beta 5$ (Fig. $5 c$ ) (171 $\pm 21 \%$ ) compared with striata from vehicle-treated mice. Such interactions are not observed after chronic fentanyl treatment. The same blots show that pretreatment with a low fentanyl dose (fent/mor group) prevents the association between RGS9-2 and MOR or between RGS9-2 and G $\beta 5$ (Fig. 5c). Increased coimmunoprecipitation of RGS9-2 with $\beta$-arrestin-2 is observed in the chronic fentanyl or fent/mor groups but not after chronic morphine administration (Fig. $5 d$ ). Notably, although chronic morphine promotes the interactions between RGS9-2 and G $\alpha$ q, it does not promote the formation of RGS9-2/PLC $\beta 3$ complexes. Chronic morphine induces the same changes in the composition of MOR-containing complexes as it does to RGS9-2-containing complexes. Consistent with the RGS9-2 co-IP findings, $\beta$-arrestin-2/MOR complexes are not observed in chronic morphine-treated animals, but they are observed in the fentanyl and fent/mor group. Chronic morphine promotes the formation of complexes between MOR and $\mathrm{G} \beta 5$, as well as between MOR and G $\alpha \mathrm{q}$ (supplemental Fig. 2, available at www.jneurosci.org as supplemental material). Similar to the co-IP assays using RGS9 antibody, pretreatment with a low fentanyl dose prevents the formation of MOR coimmunoprecipitation with either $\mathrm{G} \beta 5$ or $\mathrm{G} \alpha \mathrm{q}$ (supplemental Fig. 2, available at www.jneurosci.org as supplemental material). Knockout of the RGS9 gene does not affect the composition of MOR/G $\alpha$ subunit complexes (supplemental Fig. 3a,d, available at www.jneurosci. org as supplemental material). Thus, acute and chronic morphine promote the same MOR/G $\alpha$ subunit complexes observed in wild-type animals, but in mutant mice these complexes are no more regulated by RGS9-2. MOR and $\beta$-arrestin- 2 complexes observed after acute morphine and fentanyl administration are also observed in RGS9KO mice (supplemental Fig. 3b, available at www.jneurosci.org as supplemental material). As expected, although in wild-type mice chronic morphine promotes the formation of complexes between MOR and the RGS9 binding partner $\mathrm{G} \beta 5$, these complexes are no longer observed in RGS9KO mice (supplemental Fig. $3 c$, available at www.jneurosci.org as supplemental material).
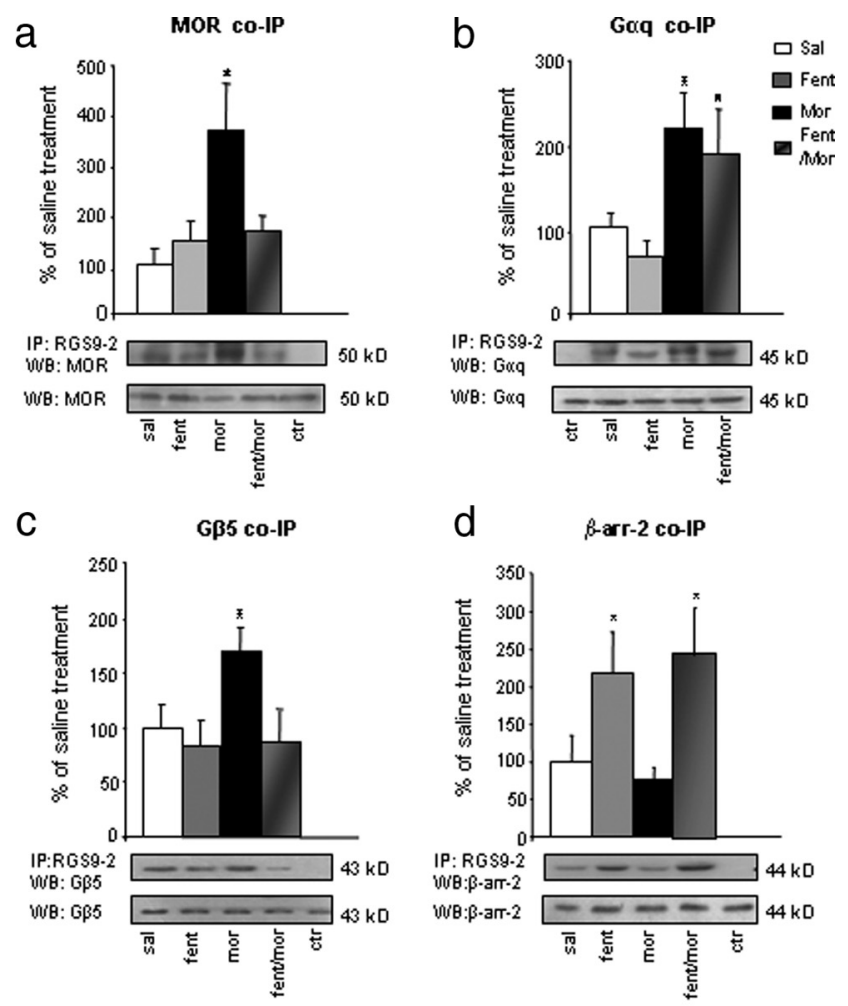

e
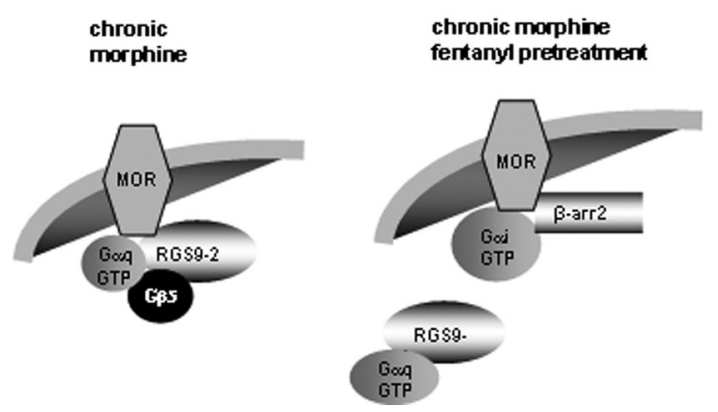

Figure 5. Signaling complexes containing RGS9-2 in striata of mice chronically treated with fentanyl or morphine. $\boldsymbol{a}$, Mice received chronic injections of saline, fentanyl, morphine, or a chronic morphine treatment in which low fentanyl dose was administered $30 \mathrm{~min}$ before each morphine injection (fent/mor). Striatal extracts were immunoprecipitated (IP) with an antiRGS9-2 antibody, and the immunoprecipitate was immunoblotted (WB) for MOR. WB for protein levels in total lysates are shown below each IP blot. Morphine promotes signaling complexes between RGS9-2 and MOR. ${ }^{*} p<0.01$ for morphine versus saline and fentanyl, one-way ANOVA followed by Dunnett's post hoc test. Striatal tissue from mice treated as in $\boldsymbol{a}$ were also immunoprecipitated with anti-RGS9-2 antibody, and the immunoprecipitate was blotted for $G \alpha q, G \beta 5$, and $\beta$-arrestin-2. As shown in $\boldsymbol{b}$, chronic morphine promotes the association between RGS9-2 and $G \alpha q$, an effect that is not significantly affected by fentanyl pretreatment. ${ }^{*} p<0.01$ for morphine or fent/mor versus saline and fentanyl, one-way ANOVA followed by Dunnett's post hoc test. As shown in c, chronic morphine promotes the formation of signaling complexes between $\mathrm{RGS} 9-2$ and $\mathrm{G} \beta 5$, an effect that is prevented by fentanyl pretreatment. $\boldsymbol{d}$ shows that complexes between RGS9-2 and $\beta$-arrestin- 2 are only formed after chronic fentanyl of fent/mor treatments. Data are expressed as means \pm SEM. $n=4-6$ per group; ${ }^{*} p<0.01$ between treatments, one-way ANOVA followed by Dunnett's post hoc test. $e$ shows a schematic representation of RGS9-2 complexes formed in striatum after chronic morphine application or chronic morphine application when morphine administration is preceded by an injection a low fentanyl dose.

\section{Manipulation of RGS9-2 complexes prevents morphine tolerance}

Finally, to test whether the chronic agonist-induced signaling complexes may subserve changes in the behavioral responses to MOR agonists, we examined whether treatments that prevent the 


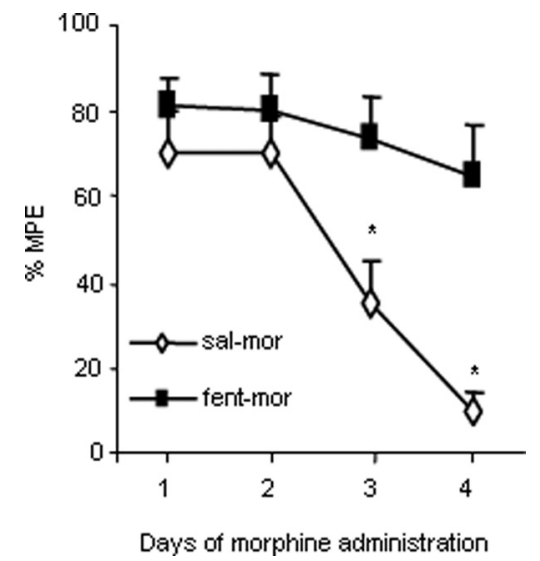

Figure 6. Pretreatment with a low fentanyl dose prevents the development of analgesic tolerance to morphine. Injection of a low fentanyl (fent) dose $(0.04 \mathrm{mg} / \mathrm{kg}) 30 \mathrm{~min}$ before morphine (mor) administration delays the development of analgesic tolerance in the hotplate assay. Analgesic responses were taken at baseline and $30 \mathrm{~min}$ after morphine injection. Control animals received saline (sal) instead of fentanyl 30 min before morphine injection. Responses are expressed as percentage maximal possible effect [\%MPE $=$ (latency - baseline)/(cutoff latency)]. Data are expressed as means \pm SEM. $n=6-8$ per group; ${ }^{*} p<0.05$, two-way ANOVA followed by Bonferroni's test.

formation of stable RGS9-2 complexes with G $\alpha$ q and G $\beta 5$ can prevent morphine tolerance. For that purpose, we used the hotplate analgesia assay and examined whether administration of a low fentanyl dose $30 \mathrm{~min}$ before morphine injection prevents the development of morphine tolerance. In particular, C57BL/6 mice were administered a low fentanyl dose $(0.04 \mathrm{mg} / \mathrm{kg}$, s.c. $)$ or saline $30 \mathrm{~min}$ before each morphine injection, and analgesic responses were assessed for 4 consecutive days. Fentanyl pretreated mice show no tolerance development compared with the control group (Fig. 6). As expected, fentanyl pretreatment has no additional effect on the analgesic responses of RGS9KO mice (data not shown).

\section{Discussion}

Our study provides evidence for a novel modulatory role of RGS9-2 on MOR signaling after acute and chronic activation. Our findings reveal brain region- and agonist-specific signal transduction events associated with MOR activation and point to RGS9-2 as a major determinant of the acute and chronic actions of opioids. This is the first evidence that a striatal protein may act as a positive or negative modulator of opiate analgesia, depending on the agonist administered. Our studies suggest that MOR couples to several $\mathrm{G} \alpha$ subunits in striatum, including $\mathrm{G} \alpha \mathrm{q}$. Furthermore, RGS9-2 differentially modulates G $\alpha$ i or G $\alpha$ q signaling in a ligand-dependent manner. Finally, we demonstrate that some of the behavioral consequences of chronic morphine administration are associated with changes in the composition of RGS9-2containing complexes. Specifically, the formation of stable MOR/ RGS9-2/G $\alpha$ q/G $\beta 5$ complexes after chronic morphine administration have detrimental effects on MOR signaling and desensitization. Based on the information we gained from coimmunoprecipitation assays on the composition of RGS9-2 complexes after acute fentanyl or morphine application, we developed simple pharmacological manipulations to prevent RGS9-2 interactions associated with analgesic tolerance to morphine. We show that, when administration of a low fentanyl dose precedes morphine administration, chronic morphine treatment does not produce analgesic tolerance. Notably, fentanyl pretreatment affects the development of morphine tolerance but not the acute analgesic actions of morphine, which do not involve G $\alpha$ q subunits (for 15 $\mathrm{mg} / \mathrm{kg}$ morphine, \%MPEs are as follows: fentanyl pretreated = $39.8 \pm 13$; saline pretreated $=42.2 \pm 12$ ).

Several groups have demonstrated that an RGS protein potentially associates with more than one type of $\mathrm{G} \alpha$ subunits. For example, RGS4 associates with G $\alpha$ i or G $\alpha$ q subunits (Huang et al., 1997; Posner et al., 1999; Tesmer et al., 2005). We show that, in striatum, after MOR activation, RGS9-2 may associate with several G $\alpha$ i subunits and with G $\alpha$ q. These findings are important, because they provide information on the mechanism of RGS9-2 actions in a particular brain region and also because they contribute to our understanding of the molecular mechanisms underlying opiate actions. Another RGS member, RGS4, does not play a role in morphine analgesia or tolerance but has a small effect as a positive modulator of fentanyl actions by dissociating from MOR after fentanyl application (Han et al., 2010).

In vitro studies have shown that $\mathrm{MOR}$ signals via different $\mathrm{G} \alpha$ subunits, but there is little information on $\mathrm{MOR} / \mathrm{G} \alpha$ subunit interactions in specific neural networks (Piros et al., 1996; Tesmer et al., 2005). Our coimmunoprecipitation assays demonstrate that, in striatum, activation of MOR by different ligands promotes the formation of RGS9-2 complexes that vary in the G $\alpha$ subunit composition and that may or may not contain G $\beta 5$. Although RGS9-2 forms complexes with several G $\alpha$ subunits after MOR activation, some of these complexes are only formed after activation of the receptor by particular ligands. Specifically, complexes between RGS9-2 and G $\alpha$ i3 are only observed after morphine administration. Fentanyl and methadone promote the formation of complexes containing RGS9-2 and G $\alpha$ q but not $\mathrm{G} \beta 5$. These are likely to be less stable complexes because they do not contain G $\beta 5$, an important determinant of RGS9-2 stability (Sondek and Siderovski, 2001). Fentanyl activation also leads to formation of complexes between RGS9-2 and PLC $\beta 3$. Increasing evidence implicates the PLC $\beta$ pathway in morphine analgesia and dependence. Behavioral analysis of PLC $\beta 3$ knock-out mice indicates that this protein acts as a negative modulator of opiate actions (Xie et al., 1999), whereas studies in guinea pig myenteric plexus tissue show adaptations in the phosphorylation of PLC $\beta 1$ and PLC $\beta 3$ isoforms to chronic morphine (Chakrabarti et al., 2003). It is thus possible that RGS9-2 acts as an effector antagonist for G $\alpha$ q because loss of the RGS9 gene leads to increased PLC $\beta 3$ phosphorylation after fentanyl administration. This hypothesis is in accordance with previous studies (Hepler et al., 1997) that have demonstrated that RGS proteins may act as effector antagonists for $\mathrm{G} \alpha$ subunits. The observed increase in PLC $\beta 3$ activity correlates with reduced analgesic response to fentanyl in the hotplate test.

Numerous reports document differences in the analgesic potency, duration of action, abuse potential, and rate of tolerance development between MOR agonists used as analgesics (Shen et al., 2000; Koch et al., 2005; Narita et al., 2006). Although morphine is a potent analgesic for several types of chronic pain, a major limit for its long-term use has to do with the development of analgesic tolerance, an effect that is observed much earlier than other opiate analgesics (Bohn et al., 1999; Inturrisi, 2002). This early tolerance development is thought to be a result of adaptive changes in MOR signaling and desensitization. Most of the information on MOR signal transduction derives from in vitro studies. Clearly, analgesia and tolerance involve complex mechanisms and several brain networks. The striatum is not typically thought to be involved in pain perception or analgesia, and most studies focus on other CNS regions, such as the dorsal horn of the spinal cord, the periaqueductal gray, and the thalamus. Recent evidence 
supports a role of the NAc in chronic pain responses (Baliki et al., 2010). Our previous work (Zachariou et al., 2006; Han et al., 2010) demonstrated that molecular adaptations in the NAc affect morphine analgesia and tolerance. We focused on RGS9-2 complexes in the striatum because of our interest on tolerance mechanisms in brain regions mediating addiction. We hypothesized that striatal proteins that dynamically modulate morphine reward and dependence also modulate opiate analgesic responsiveness and the development of tolerance. Our next aim is to investigate RGS9-2 interactions in more complex behaviors, such as locomotor sensitization to MOR agonists.

Genetic mouse models have provided an important tool for the identification of key molecules implicated in opiate analgesia and tolerance (Bohn et al., 1999; Nestler, 2001; Chakrabarti et al., 2003; Charlton et al., 2008). Because the function of several signal transduction proteins is highly determined by the complexes they form, it is essential to understand the adaptive changes in the composition of such complexes in different brain regions. Our studies suggest that, after chronic morphine treatment, the strong association between RGS9-2, G $\alpha \mathrm{q}, \mathrm{G} \beta 5$, and MOR in striatal neurons prevents the actions of several molecules involved in signal transduction and receptor desensitization and contributes to the development of analgesic tolerance. These complexes containing G $\beta 5$ would be expected to be particularly stable and thereby have a more prominent effect on receptor responsiveness (Sondek and Siderovski, 2001; Cheever et al., 2008). Although RGS9-2 is expressed in much lower levels outside the striatum, it is possible that the complexes we describe in this study modulate opiate analgesia in other brain regions as well.

Because several in vitro studies report that opioid receptors form heterodimers (Rozenfeld and Devi, 2007), the possibility that adaptive responses in signal transduction events after MOR activation involve receptor dimerization should also be considered. It is possible that the different RGS9-2/G $\alpha$ subunit complexes formed after morphine or fentanyl administration or the changes in signaling complexes formed after chronic morphine result from the formation of MOR heterodimers with $\delta$-opioid receptors (DORs) or other GPCRs. A number of recent studies implicate MOR/DOR heterodimers in opiate actions (Xie et al., 2009; Gupta et al., 2010). Although preliminary studies with the RGS9KO line show no involvement of RGS9-2 in behavioral responses to DOR agonists, we cannot exclude the possibility that RGS9-2 modulates MOR/DOR dimers in the striatum. Future studies will explore this possibility. The differential association between RGS9-2 and G $\alpha$ subunits may also be explained by the existence of more than one $\mu$-opioid receptor subtypes. There is pharmacological evidence for multiple MOR splice variants that function via distinct signaling mechanisms (Pan et al., 2005), but their expression and function in striatum has not been investigated. Future studies aim to explore the exact cell types mediating the diverse effects of opioids in striatum and to further understand the receptor and protein-protein interactions involved in acute and chronic opiate actions in this brain region.

Our biochemical and behavioral data suggest that administration of a low fentanyl dose $30 \mathrm{~min}$ before morphine treatment prevents the formation of RGS9-2/G $\alpha$ q/G $\beta 5$ complexes and delays the development of analgesic tolerance. Several reports in the past suggested that coadministration of morphine with other opioids prevents cellular events associated with tolerance. Because delayed MOR internalization/recycling leads to the development of morphine tolerance, administration of DOR agonists along with morphine in rodents prevents tolerance by promoting $\beta$-arrestin-2 function and MOR internalization (Whistler and von Zastrow, 1998). In accord with these studies, our results suggest that MOR responsiveness is highly affected by the RGS9$2 / \mathrm{G} \alpha$ subunit interactions, and interventions in these interactions may improve the function of several signal transduction molecules, including $\beta$-arrestin- 2 . Recent studies indicate that targeting RGS9-2 complexes may provide a novel approach toward the improvement of drug responses or prevention of undesired drug actions. Recent studies in primates demonstrated that overexpressing RGS9-2 in striatum may prevent some of the undesired effects of levodopa, such as dyskinesia, by limiting dopamine $\mathrm{D}_{2}$ receptor signaling (Gold et al., 2007). In the same line, the present findings demonstrate that interventions in the formation of RGS9-2 complexes comprise an efficient strategy to prevent a side effect of morphine (analgesic tolerance) without affecting the therapeutic effect (analgesia).

In summary, we investigated differences in the composition of RGS9-2-containing complexes formed during acute or chronic MOR activation by various ligands and demonstrated that RGS9-2 may act as a positive or negative regulator of opiate analgesic actions. Using information from our coimmunoprecipitation assays, we developed simple pharmacological treatments to prevent the formation of stable RGS9-2 complexes that inhibit MOR signaling. Thus, our study proposes drug administration strategies that target RGS9-2 and can be immediately applied to delay the development of morphine tolerance.

\section{References}

Arvidsson U, Riedl M, Chakrabarti S, Lee JH, Nakano AH, Dado RJ, Loh HH, Law PY, Wessendorf MW, Elde R (1995) Distribution and targeting of a mu-opioid receptor (MOR1) in brain and spinal cord. J Neurosci 15:3328-3341.

Baliki MN, Geha PY, Fields HL, Apkarian AV (2010) Predicting value of pain and analgesia: nucleus accumbens response to noxious stimuli changes in the presence of chronic pain. Neuron 66:149-160.

Ballon DR, Flanary PL, Gladue DP, Konopka JB, Dohlman HG, Thorner J (2006) DEP-domain-mediated regulation of GPCR signaling responses. Cell 126:1079-1093.

Berman DM, Gilman AG (1998) Mammalian RGS proteins: barbarians at the gates. J Biol Chem 273:1269-1272.

Bohn LM, Lefkowitz RJ, Gainetdinov RR, Peppel K, Caron MG, Lin FT (1999) Enhanced morphine analgesia in mice lacking $\beta$-arrestin 2. Science 286:2495-2498.

Cabrera-Vera TM, Hernandez S, Earls LR, Medkova M, Sundgren-Andersson AK, Surmeier DJ, Hamm HE (2004) RGS9-2 modulates D2 dopamine receptor-mediated $\mathrm{Ca}^{2+}$ channel inhibition in rat striatal cholinergic interneurons. Proc Natl Acad Sci U S A 101:16339-16344.

Chakrabarti S, Liu NJ, Gintzler AR (2003) Reciprocal modulation of phospholipase C beta isoforms: adaptation to chronic morphine. Proc Natl Acad Sci U S A 100:13686-13691.

Charlton JJ, Allen PB, Psifogeorgou K, Chakravarty S, Gomes I, Neve RL, Devi LA, Greengard P, Nestler EJ, Zachariou V (2008) Multiple actions of spinophilin modulate mu opioid receptor function. Neuron 58:238-247.

Cheever ML, Snyder JT, Gershburg S, Siderovski DP, Harden TK, Sondek J (2008) Crystal structure of the multifunctional RGS9-2-Gb5 complex. Nat Struct Mol Biol 15:155-162.

Chen CK, Eversole-Cire P, Zhang H, Mancino V, Chen YJ, He W, Wensel TG, Simon MI (2003) Instability of GGL domain containing RGS proteins in mice lacking the $G$ protein beta subunit $G \beta 5$. Proc Natl Acad Sci U S A 100:6604-6609.

Contet C, Kieffer BL, Befort K (2004) Mu opioid receptor: a gateway to drug addiction. Curr Opin Neurobiol 14:370-378.

Dohlman HG, Thorner J (1997) RGS proteins and signaling by heterotrimeric G proteins. J Biol Chem 272:3871-3874.

Eitan S, Bryant CD, Saliminejad N, Yang YC, Vojdani E, Keith D Jr, Polakiewicz R, Evans CJ (2003) Brain region-specific mechanisms for acute morphinmitogen-activated protein kinase modulation and distinct patterns of activation during analgesic tolerance and locomotor sensitization. J Neurosci 23:8360-8369.

Gold SJ, Ni YG, Dohlman HG, Nestler EJ (1997) Regulators of G-protein 
signaling (RGS) proteins: region-specific expression of nine subtypes in rat brain. J Neurosci 17:8024-8037.

Gold SJ, Hoang CV, Potts BW, Porras G, Pioli E, Kim KW, Nadjar A, Qin C, LaHoste GJ, Li Q, Bioulac BH, Waugh JL, Gurevich E, Neve RL, Bezard E (2007) RGS9-2 negatively modulates L-3,4-dihydroxyphenylalanineinduced dyskinesia in experimental Parkinson's disease. J Neurosci 27: $14338-14348$.

Gupta A, Mulder J, Gomes I, Rozenfeld R, Bushlin I, Ong E, Lim M, Maillet E, Junek M, Cahill CM, Harkany T, Devi LA (2010) Increased abundance of opioid receptor heteromers after chronic morphine administration. Sci Signal 3:ra54.

Haberstock-Debic H, Kim KA, Yu YJ, von Zastrow M (2005) Morphine promotes rapid, arrestin-dependent endocytosis of $\mu$-opioid receptors in striatal neurons. J Neurosci 25:7847-7857.

Han MH, Renthal W, Ring RH, Rahman Z, Psifogeorgou K, Howland D, Birnbaum S, Young K, Neve R, Nestler EJ, Zachariou V (2010) Brain region specific actions of regulator of $\mathrm{G}$ protein signaling 4 oppose morphine reward and dependence but promote analgesia. Biol Psychiatry 67:761-769.

He W, Lu L, Zhang X, El-Hodiri HM, Chen CK, Slep KC, Simon MI, Jamrich M, Wensel TG (2000) Modules in the photoreceptor RGS9-1.Gbeta 5L GTPase-accelerating protein complex control effector coupling, GTPase acceleration, protein folding, and stability. J Biol Chem 275:37093-37100.

Hepler JR, Berman DM, Gilman AG, Kozasa T (1997) RGS and GAIP are GTPase activating proteins for Gq alpha and block activation of phospholipase C beta by gamma-thio-GTP-Gq-alpha. Proc Natl Acad Sci U S A 94:428-432.

Huang C, Hepler JR, Gilman AG, Mumby SM (1997) Attenuation of Giand Gq-mediated signaling by expression of RGS4 or GAIP in mammalian cells. Proc Natl Acad Sci U S A 94:6159-6163.

Inturrisi CE (2002) Clinical pharmacology of opioids for pain. Clin J Pain 18 [Suppl 4]:S3-13.

Jayaraman M, Zhou H, Jia L, Cain MD, Blumer KJ (2009) R9AP and R7BP: traffic cops for the RGS7 family in phototransduction and neuronal GPCR signaling. Trends Pharmacol Sci 30:17-24.

Jin J, Kittanakom S, Wong V, Reyes BA, Van Bockstaele EJ, Stagljar I, Berrettini W, Levenson R (2010) Interaction of the mu-opioid receptor with GPR177 (Wntless) inhibits Wnt secretion: potential implications for opioid dependence. BMC Neurosci 11:33-37.

Koch T, Widera A, Bartzsch K, Schulz S, Brandenburg LO, Wundrack N, Beyer A, Grecksch G, Höllt V (2005) Receptor endocytosis counteracts the development of opioid tolerance. Mol Pharmacol 67:280-287.

Kovoor A, Seyffarth P, Ebert J, Barghshoon S, Chen CK, Schwarz S, Axelrod JD, Cheyette BN, Simon MI, Lester HA, Schwarz J (2005) D2 dopamine receptors colocalize regulator of $G$ protein signalling 9-2 via the RGS9 DEP domain, and RGS9 knockout mice develop dyskinesias associated with dopamine pathways. J Neurosci 25:2157-2165.

Kreek MJ (2001) Drug addictions. Molecular and cellular endpoints. Ann NY Acad Sci 937:27-49.

Martemyanov KA, Lishko PV, Calero N, Keresztes G, Sokolov M, Strissel KJ, Leskov IB, Hopp JA, Kolesnikov AV, Chen CK, Lem J, Heller S, Burns ME, Arshavsky VY (2003) The DEP domain determines subcellular targeting of the GTPase activating protein RGS9 in vivo. J Neurosci 23:10175-10181.

Martemyanov KA, Yoo PJ, Skiba NP, Arshavsky VY (2005) R7BP, a novel neuronal protein interacting with RGS proteins and the R7 subfamily. J Biol Chem 280:5133-5136.

Muller DL, Unterwald EM (2004) In vivo regulation of extracellular signalregulated protein kinase (ERK) and protein kinase B (Akt) phosphorylation by acute and chronic morphine. J Pharmacol Exp Ther 310:774-782.

Mumby SM, Gilman AG (1991) Synthetic peptide antisera with determined specificity for $\mathrm{G}$ protein alpha or beta subunits. Methods Enzymol 195:215-233.

Mundell SJ, Loudon RP, Benovic JL (1999) Characterization of G proteincoupled receptor regulation in antisense mRNA-expressing cells with reduced arrestin levels. Biochemistry 38:8723-8732.

Narita M, Suzuki M, Narita M, Niikura K, Nakamura A, Miyatake M, Yajima Y, Suzuki T (2006) mu-Opioid receptor internalization-dependent and -independent mechanisms of the development of tolerance to mu-opioid receptor agonists: comparison between etorphine and morphine. Neuroscience 138:609-619.

Nestler EJ (2001) Molecular basis of long-term underlying addiction. Nat Rev Neurosci 2:119-128.

Pan YX, Xu J, Bolan E, Moskowitz HS, Xu M, Pasternak GW (2005) Identification of four novel exon 5 splice variants of the mouse mu-opioid receptor gene: functional consequences of C-terminal splicing. Mol Pharmacol 68:866-875.

Piros ET, Hales TG, Evans CJ (1996) Functional analysis of cloned opioid receptors in transfected cell lines. Neurochem Res 21:1277-1285.

Posner BA, Mukhopadhyay S, Tesmer JJ, Gilman AG, Ross EM (1999) Modulation of the affinity and selectivity of RGS protein interaction with $\mathrm{G}$ alpha subunits by a conserved asparagine/serine residue. Biochemistry 38:7773-7779.

Psifogeorgou K, Papakosta P, Russo SJ, Neve RL, Kardassis D, Gold SJ, Zachariou V (2007) RGS9-2 is a negative modulator of mu opioid receptor function. J Neurochem 103:617-625.

Rahman Z, Gold SJ, Potenza MN, Cowan CW, Ni YG, He W, Wensel TG, Nestler EJ (1999) Cloning and characterization of RGS9-2, a striatal enriched alternatively spliced product of the RGS9 gene. J Neurosci 19: 2016-2026.

Rahman Z, Schwarz J, Gold SJ, Zachariou V, Wein MN, Choi KH, Kovoor A, Chen CK, DiLeone RJ, Schwarz SC, Selley DE, Sim-Selley LJ, Barrot M, Luedtke RR, Self D, Neve RL, Lester HA, Simon MI, Nestler EJ (2003) RGS9 modulates dopamine signaling in the basal ganglia. Neuron 38: 941-952.

Rozenfeld R, Devi LA (2007) Receptor heterodimerization leads to a switch in signaling: beta-arrestin2-mediated ERK activation by mu-delta opioid receptor heterodimers. FASEB J 21:2455-2465.

Shen J, Benedict Gomes A, Gallagher A, Stafford K, Yoburn BC (2000) Role of cAMP-dependent protein kinase (PKA) in opioid agonist-induced muopioid receptor downregulation and tolerance in mice. Synapse 38: 322-327.

Sondek J, Siderovski DP (2001) G- $\gamma$ like domains: new frontiers in G protein signalling and $\beta$-propeller scaffolding. Biochem Pharmacol 61:1329-1337.

Terzi D, Stergiou E, King SL, Zachariou V (2009) RGS proteins in neuropsychiatric disorders. Prog Mol Biol Translational Sci Vol 86C:299-333.

Tesmer VM, Kawano T, Shankaranarayanan A, Kozasa T, Tesmer JJ (2005) Snapshot of activated G proteins at the membrane: the Galphaq-GRK2Gbetagamma complex. Science 310:1686-1690.

Traynor JR, Neubig RR (2005) Regulators of G protein signaling and drugs of abuse. Mol Interv 5:30-41.

Traynor JR, Terzi D, Caldarone BJ, Zachariou V (2009) RGS9-2: probing an intracellular modulator of behaviour as a drug target. Trends Pharmacol Sci 30:105-111.

Whistler JL, von Zastrow M (1998) Morphine-activated opioid receptors elude desensitization by beta-arrestin. Proc Natl Acad Sci U S A 95: 9914-9919.

Witherow DS, Tovey SC, Wang Q, Willars GB, Slepak VZ (2003) G beta 5.RGS7 inhibits Galpha q-mediated signaling via a direct protein-protein interaction. J Biol Chem 278:21307-21313.

Xie W, Samoriski GM, McLaughlin JP, Romoser VA, Smrcka A, Hinkle PM, Bidlack JM, Gross RA, Jiang H, Wu D (1999) Genetic alterations in phospholipase $\mathrm{C}$ beta3 expression modulates behavioral and cellular responses to opioids. Proc Natl Acad Sci U S A 96:10385-10390.

Xie WY, He Y, Yang YR, Li YF, Kang K, Xing BM, Wang Y (2009) Disruption of Cdk5 associated phosphorylation of residue threonine-161 of the $\delta$-opioid receptor: impaired receptor function and attenuated morphine antinociceptive tolerance. J Neurosci 29:3551-35564.

Zachariou V, Georgescu D, Sanchez N, Rahman Z, DiLeone R, Berton O, Neve RL, Sim-Selley LJ, Selley DE, Gold SJ, Nestler EJ (2003) Essential role for RGS9 in opiate action. Proc Natl Acad Sci 100:13656-13661.

Zachariou V, Bolanos CA, Selley DE, Theobald D, Cassidy MP, Kelz MB, Shaw-Lutchman T, Berton O, Sim-Selley LJ, Dileone RJ, Kumar A, Nestler EJ (2006) An essential role for DeltaFosB in the nucleus accumbens in morphine action. Nat Neurosci 9:205-211. 